\title{
NiO Nanoparticles Synthesis by Chemical Precipitation and Effect of Applied Surfactant on Distribution of Particle Size
}

\author{
Y. Bahari Molla Mahaleh, S. K. Sadrnezhaad, and D. Hosseini \\ Materials \& Energy Research Center, P.O. Box 14155-4777, Karaj, Iran \\ Correspondence should be addressed to Y. Bahari Molla Mahaleh, yaser_bahari@yahoo.com
}

Received 25 September 2008; Accepted 24 December 2008

Recommended by Min Xu

Production of $\mathrm{NiO}$ by chemical precipitation is the approach utilized in this work. Materials mainly used in this project are nickel nitrate hex hydrate (as a basic material), sodium hydroxide (as a precipitator material), and the following surfactants (for reduction in particle size). Applied surfactants are in two kinds: polymeric (PVP, PEG) and cationic (CTAB) surfactants, 1.0 gram. Nanopowders properties are identified by TG, FTIR, XRD, SEM, and TEM. The results obtained confirm the presence of nickel oxide nanopowders produced during chemical precipitation.

Copyright (c) 2008 Y. Bahari Molla Mahaleh et al. This is an open access article distributed under the Creative Commons Attribution License, which permits unrestricted use, distribution, and reproduction in any medium, provided the original work is properly cited.

\section{INTRODUCTION}

Nanomaterials exhibit significantly mechanical, electronic, magnetic, thermal, catalytic properties, and optical properties in comparison with their bulk counterparts, and have extensively attracted interests $[1,2]$. In recent years, there has been an increasing interest in the synthesis of nanosized crystalline metal oxides because of their large surface areas, unusual adsorptive properties, surface defects, and fast diffusivities [3]. NiO nanoparticles may have many applications such as in the manufacture of electrochromic, films, magnetic materials, p-type transparent conducting films, gas sensors, catalyst, alkaline batteries cathode, and solid oxide fuel cells anode [1-10]. Several methods (mechanical or chemical) have been used and developed for synthesizing crystalline oxide powders in nanoscale dimensions. In many of them, the main objective is to reduce the costs of chemical synthesis and to produce materials for technological applications [11]. The purpose of this work is the synthesis of $\mathrm{NiO}$ nanoparticles by the chemical precipitation process in the presence of sodium hydroxide, which is a simple way and low in cost since the starting materials are few and inexpensive.

\section{MATERIALS AND METHOD}

The reagents used for the synthesis of nanopowders were prepared from MERC with $99.0 \%$ purification. The main materials were nickel nitrate hex hydrate $\left(\mathrm{Ni}\left(\mathrm{NO}_{3}\right)_{2} \cdot 6 \mathrm{H}_{2} \mathrm{O}\right)$, sodium hydroxide $(\mathrm{NaOH})$, polyvinilpyrolidone (PVP, $\mathrm{MW}=65000)$, polyethylene glycol $(\mathrm{PEG}, \mathrm{MW}=15000)$, and cetyl trimethyl ammonium bromide (CTAB). First, we prepared two separate solutions; one a solution of $8.7 \mathrm{~g}$ of nickel nitrate in $60 \mathrm{~mL}$ of deionized water and the other contains a solution of $3.0 \mathrm{~g}$ sodium hydroxide in $150 \mathrm{~mL}$ of deionized water. Amount of $1 \mathrm{~g}$ of mentioned surfactants in three different experiments added to latter solution. Next, the former solution was added dropwise into the later. The mixed solution was stirred by magnetic stirring apparatus $(1000 \mathrm{rpm})$ at room temperature. The resultant light-green solution was filtered, and then washed with deionized water and ethanol for $5-10$ times and was dried at $50^{\circ} \mathrm{C}$ for 24 hours, then calcined at $300^{\circ} \mathrm{C}, 450^{\circ} \mathrm{C}$, and $600^{\circ} \mathrm{C}$ for 2 hours for three different samples. The surfactants were removed after the mentioned processes. Main reactions occur during the experimental procedure can be written briefly as follows: 


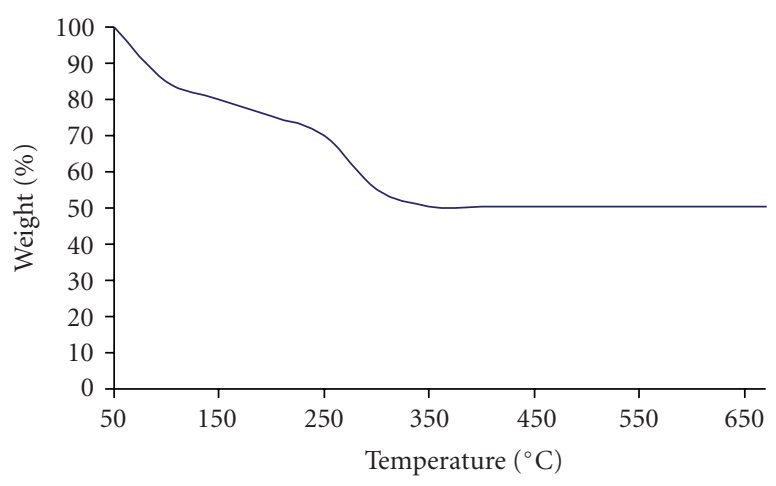

Figure 1: Thermograph of the $\mathrm{NiO}$ precursor.

$$
\begin{gathered}
2 \mathrm{NaOH}_{(\mathrm{s})} \longrightarrow 2 \mathrm{Na}^{+}{ }_{(\mathrm{aq})}+2 \mathrm{OH}^{-}{ }_{(\mathrm{aq})}, \\
\mathrm{Ni}\left(\mathrm{NO}_{3}\right)_{2} \cdot 6 \mathrm{H}_{2} \mathrm{O}_{(\mathrm{s})} \longrightarrow \mathrm{Ni}^{2+}{ }_{(\mathrm{aq})}+2 \mathrm{NO}_{3}{ }^{-}{ }_{(\mathrm{aq})}+6 \mathrm{H}_{2} \mathrm{O}_{(\mathrm{aq})}, \\
\mathrm{Ni}^{2+}{ }_{(\mathrm{aq})}+2 \mathrm{OH}^{-}{ }_{(\mathrm{aq})}+x \mathrm{H}_{2} \mathrm{O}_{(\mathrm{aq})} \longrightarrow \mathrm{Ni}(\mathrm{OH})_{2} \cdot x \mathrm{H}_{2} \mathrm{O}_{(\mathrm{s})} \\
\mathrm{Ni}(\mathrm{OH})_{2} \cdot x \mathrm{H}_{2} \mathrm{O}_{(\mathrm{s})} \stackrel{50-100}{\longrightarrow} \mathrm{Ni}(\mathrm{OH})_{2(\mathrm{~s})}+x \mathrm{H}_{2} \mathrm{O}_{(\mathrm{g})} \uparrow \\
\mathrm{Ni}(\mathrm{OH})_{2(\mathrm{~s})} \stackrel{300}{\longrightarrow} \mathrm{NiO}_{(\mathrm{s})}+\mathrm{H}_{2} \mathrm{O}_{(\mathrm{g})} \uparrow
\end{gathered}
$$

\section{RESULTS AND DISCUSSION}

Figure 1 shows the TG curve of $\mathrm{NiO}$ precursor. It can be seen that the thermal decomposition of the molecule can be divided to four separated regions. The first one is related to the evaporation of the absorbed water between $50^{\circ} \mathrm{C}$ and $100^{\circ} \mathrm{C}$, at which most of the water will be vanished. In the second region, the residue water will be evaporated by a temperate rate. We have a significant weight loss in the third region because of calcination of structural water. The structural water, which has band structure with nickel and oxygen atoms inside the molecule, will be eliminated before $300^{\circ} \mathrm{C}$. This event may lead to pure $\mathrm{NiO}$ particles. In the last region, the molecule will be stable and the weight of molecule is nearly constant without any other of weight loss.

The IR spectrum of the precursor (Figure 2(a)) exhibits absorption peaks. The broad absorption band centered at $3438 \mathrm{~cm}^{-1}$ is attributed to the band $\mathrm{O}-\mathrm{H}$ stretching vibrations, and the band at $1649 \mathrm{~cm}^{-1}$ is attributed to bending mode $(\mathrm{H}-\mathrm{O}-\mathrm{H})$. The band at $1383 \mathrm{~cm}^{-1}$ is primarily due to the banding vibration of ionic $\mathrm{CO}_{3}{ }^{2-}$. The three bands appearing around $1061,830,700 \mathrm{~cm}^{-1}$ confirm the presence of $\mathrm{C}-\mathrm{O}$ in the precursor, and it vanishes after calcination (in Figure 2(b)). The strong band at $423 \mathrm{~cm}^{-1}$ corresponds to the banding vibration of $\mathrm{NiO}$. The band at $3445 \mathrm{~cm}^{-1}$ and the band in $1383 \mathrm{~cm}^{-1}$ in Figure 2(b) are due to the fact that the calcined powder tends to physically absorb water and carbonate ion.

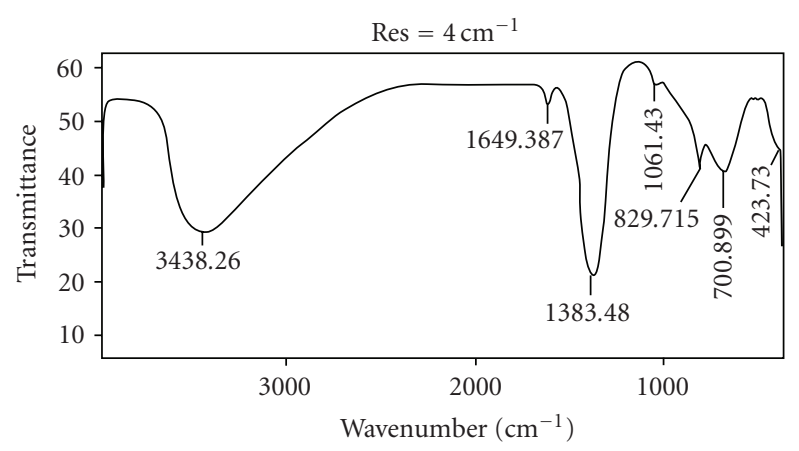

(a)

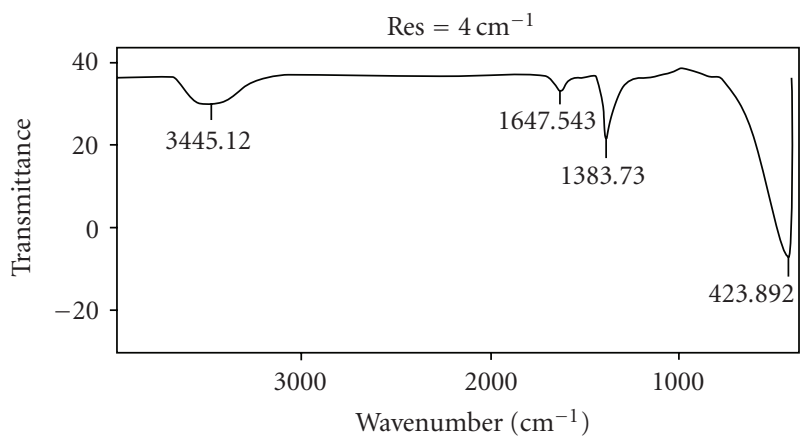

(b)

FIgure 2: The FT-IR spectra. (a) Precursor and (b) calcined powder.

The XRD pattern of precursor and final product (after calcination) are shown in Figure 3. Comparing to XRD standard table the diffraction peaks in Figure 3 , a (precursor) is in agreement with the diffraction peaks of $\mathrm{Ni}(\mathrm{OH})_{2} \cdot \mathrm{H}_{2} \mathrm{O}$ which is consistent with predicted reactions. Main crystallographic planes in precursor XRD pattern (Figure $3(\mathrm{a})$ ) are (001), (100), (101), (102), (110), and (111). In XRD-calcined product pattern (Figure 3(b)), crystallographic planes such as (111), (200), (220), and (311) are appeared, which indicates $\mathrm{NiO}$ particles crystallization and elimination of the former phase (nickel hydroxide). First peak in each case of Figure 3 is referring to instrumental error based on the fact that our instrument made this error for all samples. It may be concluded that the product is nickel oxide without any disturbing component. By increasing calcination temperature (Figures 3(c) and 3(d)), it will result in sharper diffraction peaks, which means that bigger particle size may be generated from higher calcination temperatures. So calcination in low temperatures (near $300^{\circ} \mathrm{C}$ ) is better than that in high temperatures. Figure 4 shows the SEM images of the product synthesized. It is clear that in all cases (Figures 4(a), 4(b), and 4(c)), $\mathrm{NiO}$ nanoparticles were successfully prepared. For comparing the effect of surfactant on particle size distribution, however, the particle size was identified by measuring 100 particles in each case. Figure 5 shows the results of such identification. The ranges of particle sizes vary between $25 \mathrm{~nm}$ and $65 \mathrm{~nm}$. 


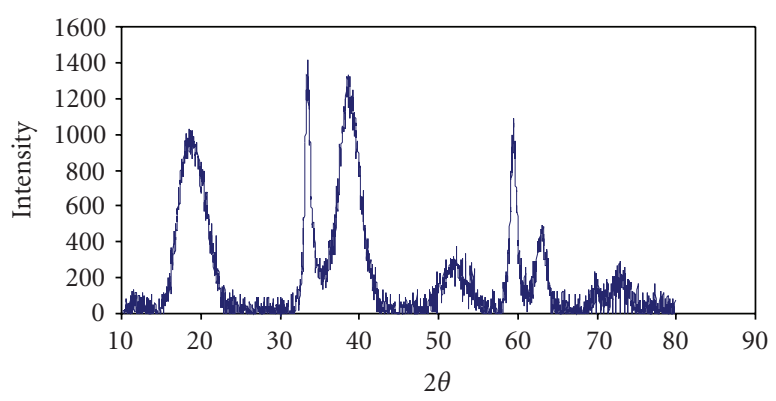

(a)

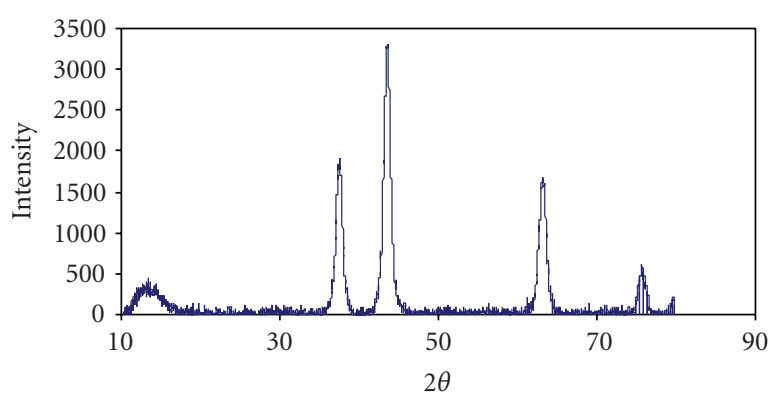

(b)

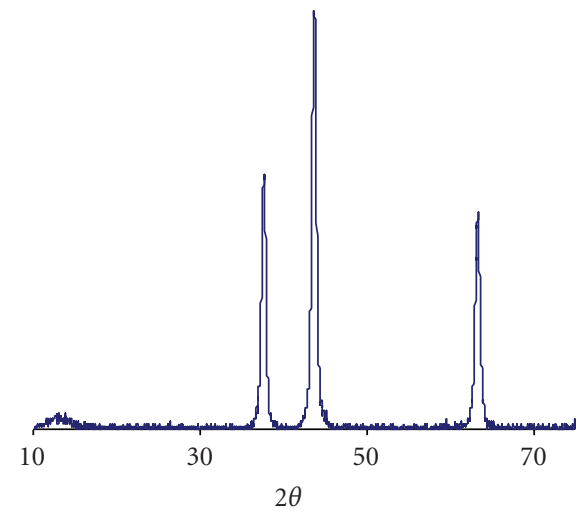

(c)

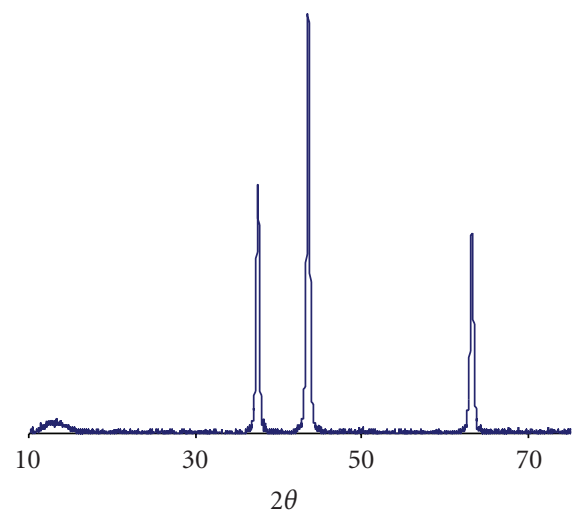

(d)

FIgure 3: XRD patterns. (a) Precursor and calcined powder at (b) 300 , (c) 450 , and (d) $600^{\circ} \mathrm{C}$.

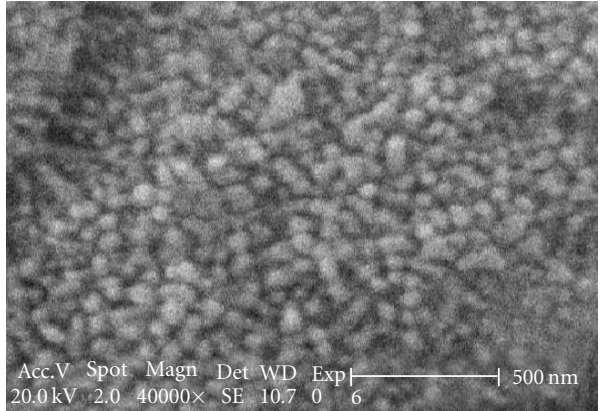

(a)

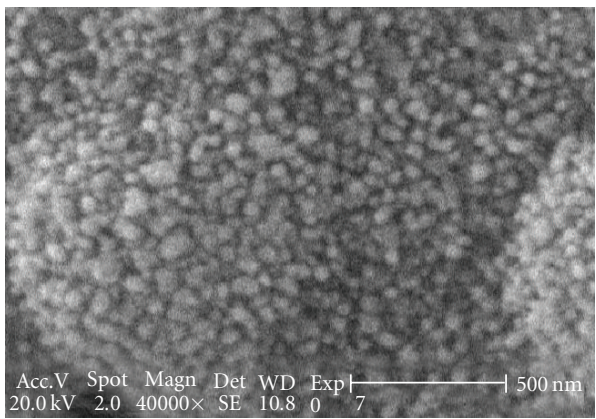

(b)

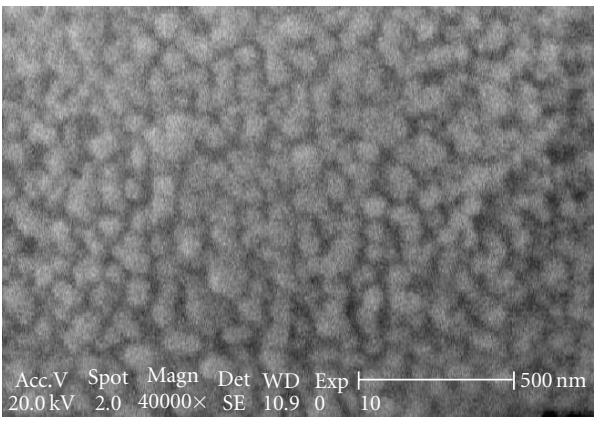

(c)

FIgure 4: The SEM image of NiO nanoparticles. (a) PVP, (b) PEG, and (c) CTAB.

In the case of PVP, the maximum size of particles is less than $55 \mathrm{~nm}$, and thus it results in small size particle (Figure 4(a)). Most of the particles in PEG sample have the same and uniform size $(35-45 \mathrm{~nm})$, and most of particles (near $80 \%$ ) have less than $45 \mathrm{~nm}$ size (Figure 4(b)). It seems that $\mathrm{CTAB}$ has a weaker effect on the reduction in particle size rather than PVP or PEG because the majority of particles (near 70\%) have a larger size than $45 \mathrm{~nm}$ (Figure 4(c)).

Figure 6 is a TEM image of the $\mathrm{NiO}$ nanoparticles with PEG surfactant. It can be seen that the uniform $\mathrm{NiO}$ nanoparticles had narrow size distribution and sphere shapes with weak agglomeration. Most of the particle sizes are less than $45 \mathrm{~nm}$, which confirms the SEM results. 


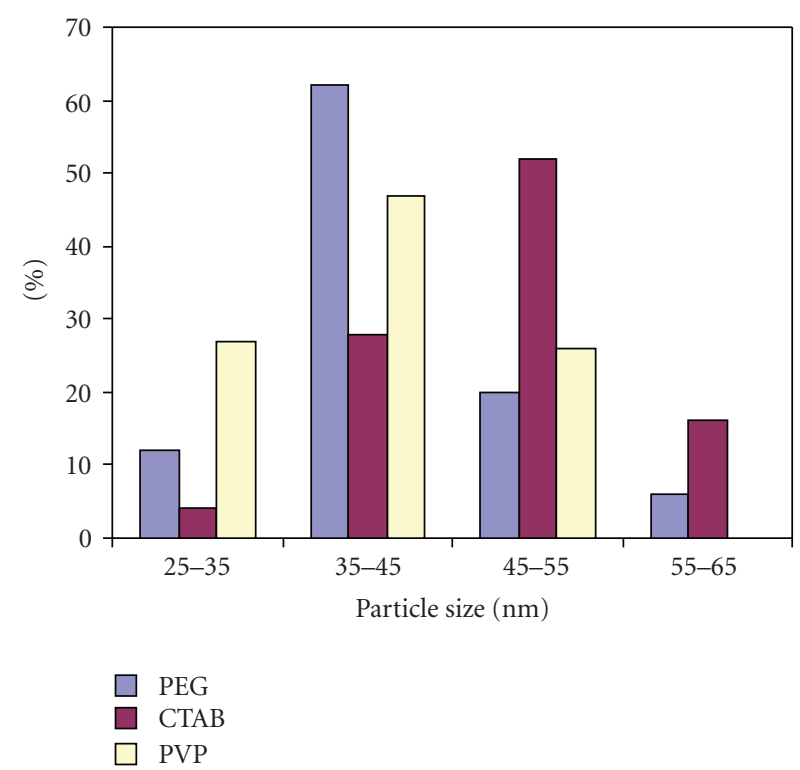

FiguRE 5: Distribution of particle sizes.

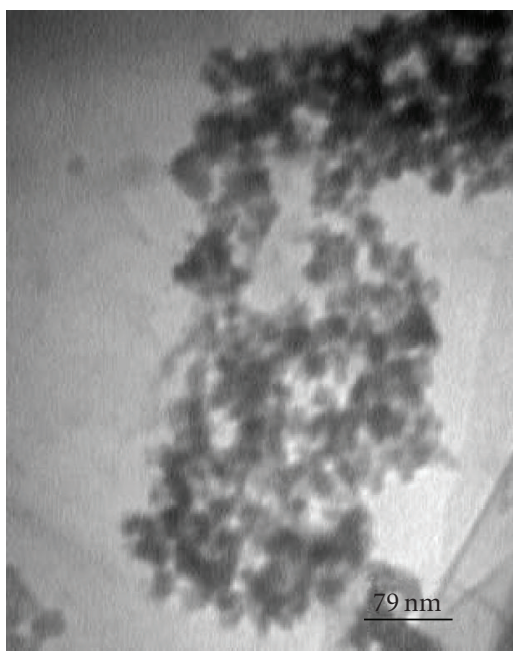

Figure 6: TEM image of the NiO nanoparticles (PEG $1 \mathrm{~g}$ ).

\section{CONCLUSION}

$\mathrm{NiO}$ nanopowder was successfully prepared by chemical precipitation method, using nickel nitrate hex hydrate and sodium hydroxide as raw materials. The majority of obtained $\mathrm{NiO}$ nanopowders had an average particle size less than $50 \mathrm{~nm}$ in all cases. It sounds that PEG and PVP are more useful surfactants than $\mathrm{CTAB}$ for reduction in size of particles, exhibitation narrow size distribution, and weak agglomeration.

\section{ACKNOWLEDGMENT}

The authors would like to thank the Electrochemistry Laboratory of Materials \& Energy Research Center for its support.

\section{REFERENCES}

[1] Q. Li, L.-S. Wang, B.-Y. Hu, C. Yang, L. Zhou, and L. Zhang, "Preparation and characterization of $\mathrm{NiO}$ nanoparticles through calcination of malate gel," Materials Letters, vol. 61, no. 8-9, pp. 1615-1618, 2007.

[2] X. Xin, Z. Lü, B. Zhou, et al., "Effect of synthesis conditions on the performance of weakly agglomerated nanocrystalline NiO," Journal of Alloys and Compounds, vol. 427, no. 1-2, pp. 251-255, 2007.

[3] Y. Wu, Y. He, T. Wu, T. Chen, W. Weng, and H. Wan, "Influence of some parameters on the synthesis of nanosized $\mathrm{NiO}$ material by modified sol-gel method," Materials Letters, vol. 61, no. 14-15, pp. 3174-3178, 2007.

[4] K.-C. Min, M. Kim, Y.-H. You, et al., "NiO thin films by MOCVD of $\mathrm{Ni}(\mathrm{dmamb})_{2}$ and their resistance switching phenomena," Surface \& Coatings Technology, vol. 201, no. 2223, pp. 9252-9255, 2007.

[5] I. Hotovy, J. Huran, L. Spiess, H. Romanus, D. Buc, and R. Kosiba, "NiO-based nanostructured thin films with Pt surface modification for gas detection," Thin Solid Films, vol. 515, no. 2, pp. 658-661, 2006.

[6] S. A. Needham, G. X. Wang, and H. K. Liu, "Synthesis of $\mathrm{NiO}$ nanotubes for use as negative electrodes in lithium ion batteries," Journal of Power Sources, vol. 159, no. 1, pp. 254257, 2006.

[7] S. Thota and J. Kumar, "Sol-gel synthesis and anomalous magnetic behaviour of $\mathrm{NiO}$ nanoparticles," Journal of Physics and Chemistry of Solids, vol. 68, no. 10, pp. 1951-1964, 2007.

[8] Y.-Z. Zheng and M.-L. Zhang, "Preparation and electrochemical properties of nickel oxide by molten-salt synthesis," Materials Letters, vol. 61, no. 18, pp. 3967-3969, 2007.

[9] Y. Wu, Y. He, T. Wu, T. Chen, W. Weng, and H. Wan, "Influence of some parameters on the synthesis of nanosized $\mathrm{NiO}$ material by modified sol-gel method," Materials Letters, vol. 61, no. 14-15, pp. 3174-3178, 2007.

[10] X. Ni, Y. Zhang, D. Tian, H. Zheng, and X. Wang, "Synthesis and characterization of hierarchical $\mathrm{NiO}$ nanoflowers with porous structure," Journal of Crystal Growth, vol. 306, no. 2, pp. 418-421, 2007.

[11] E. A. Souza, J. G. S. Duque, L. Kubota, and C. T. Meneses, "Synthesis and characterization of $\mathrm{NiO}$ and $\mathrm{NiFe}_{2} \mathrm{O}_{4}$ nanoparticles obtained by a sucrose-based route," Journal of Physics and Chemistry of Solids, vol. 68, no. 4, pp. 594-599, 2007. 

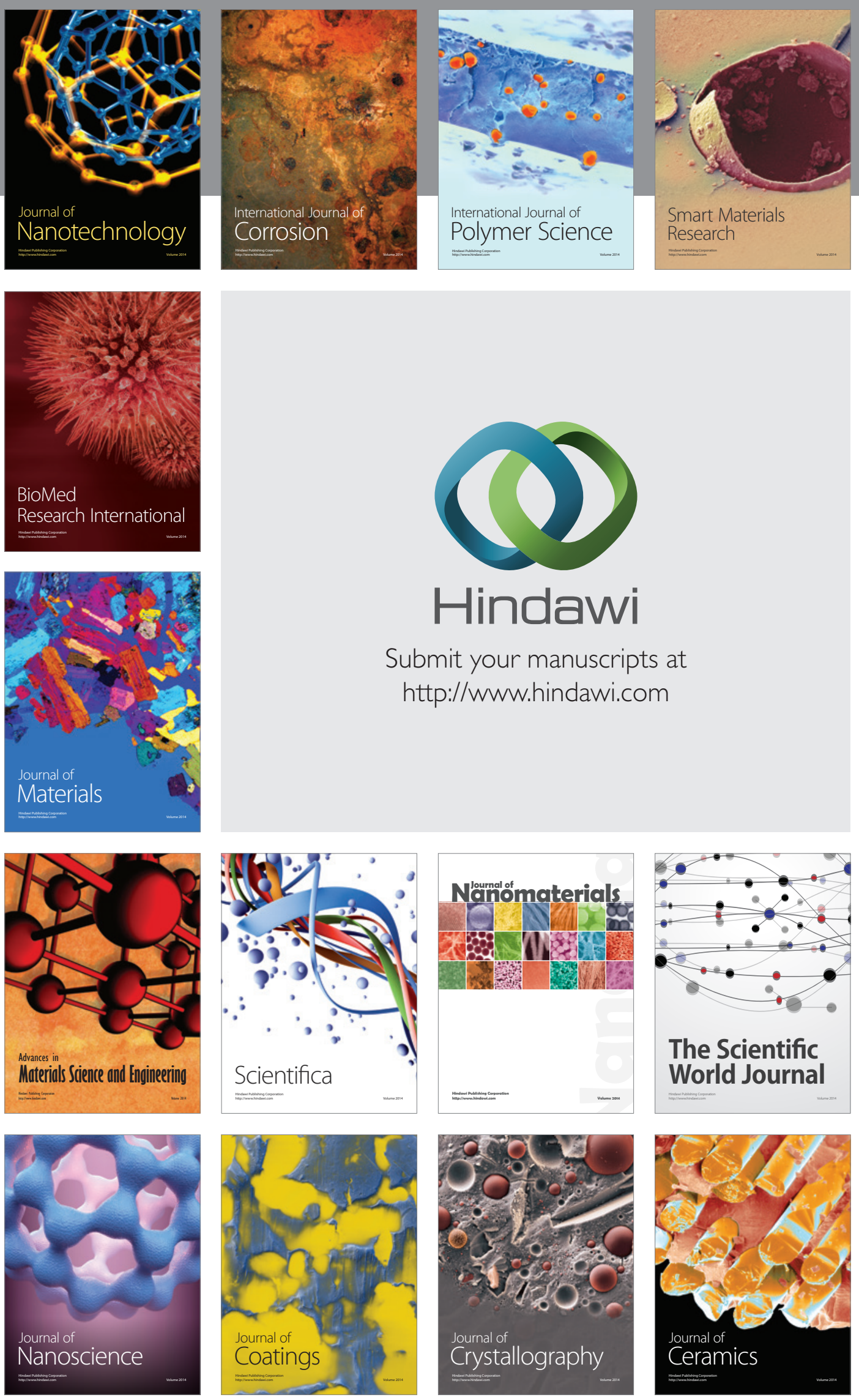

The Scientific World Journal

Submit your manuscripts at

http://www.hindawi.com

\section{World Journal}

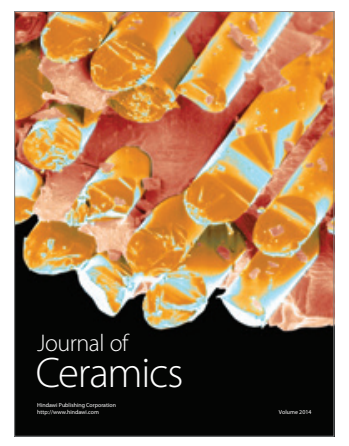

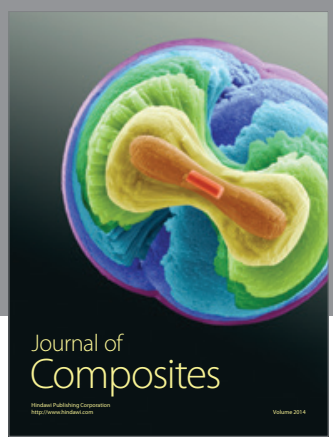
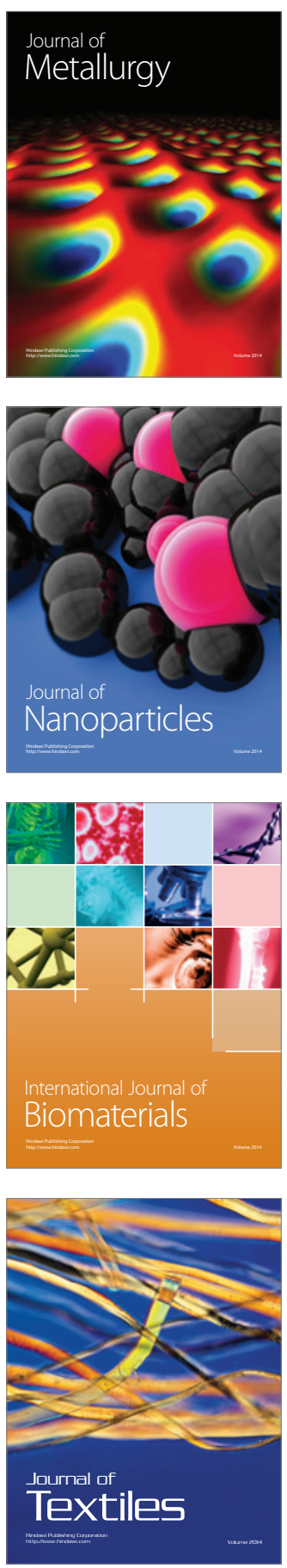